\title{
The Use of Laparoscopy in the Management of Trauma Patients Brief review
}

"Yehia B. A. El-Bendary, Juhaina Al-Adawi, Hani Al-Qadhi

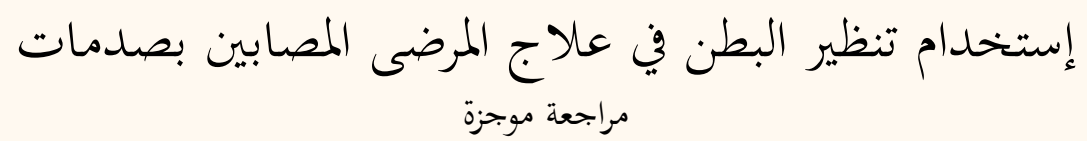

$$
\text { يحيى البندارى أحمد البندارى، جهينة آل العدوية، هـاني القاضي }
$$

ABSTRACT: Laparoscopy is one of the most effective intervention modalities, resulting in improved outcomes for major surgeries. In the past decade, the laparoscopic approach in trauma patients has shown better diagnostic outcomes than traditional laparotomies. Furthermore, this approach is cost-effective, significantly reduces the length of hospital stay and contributes to reduced complication rates. However, the use of laparoscopies in trauma cases is generally restricted to patients with normal haemodynamic parameters and is contraindicated for individuals with head injuries. With advances in knowledge and improved training, laparoscopies can also be used in the treatment of other conditions, such as diaphragmatic injuries and organ lacerations. This article briefly reviews the extent of laparoscopy use and its significance in the management of trauma patients.

Keywords: Laparoscopy; Laparotomy; Trauma; Abdominal Injuries; Diaphragm; Penetrating Wounds; Acute Abdomen.

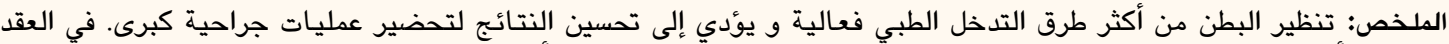

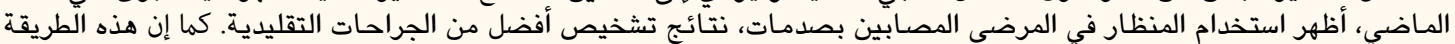

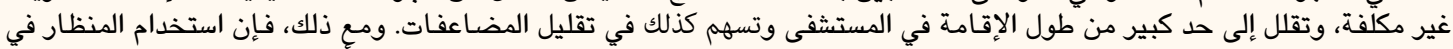

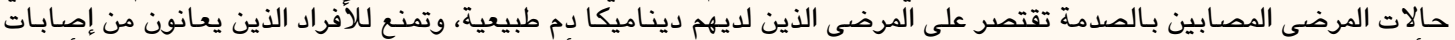

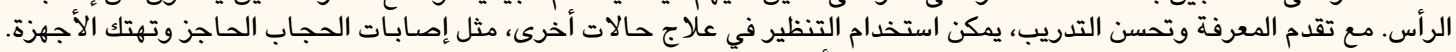

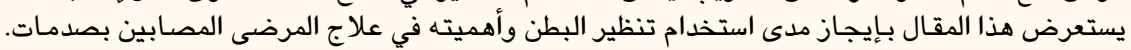
مفتاح الكلمات: تنظير البطن؛ نتح البطن؛ صدمة؛ إصـابات البطن؛ الحجاب الحاجز؛ الجروح المخترقة؛ البطن الحاد.

$\mathrm{T}$ RAUMA-WHETHER FROM A BLUNT OR PENetrating injury, an explosion or a fall-is one of the leading causes of mortality in young patients worldwide. Multiple guidelines and management modalities have been suggested to provide optimal care and prognostic outcomes for these patients with minimal morbidity. One continuously evolving method that allows medical personnel to meet the specifications outlined in these guidelines is the laparoscopy. Laparoscopic interventions have positively affected patient outcomes for both trauma and surgical cases, including cholecystectomy, appendectomy, visceral perforation and hernia repair cases. ${ }^{1}$ The main goal of a laparoscopy is to use the least invasive method to identify or exclude organ and visceral injuries and, if possible, reach a diagnosis. Therefore, with evolving techniques and improved practice, laparoscopy may potentially be a therapeutic option for patients with selected traumatic injuries.
In the management of trauma patients, laparoscopies have proven to be safer and more cost-effective than laparotomies in terms of hospital stay and the prevention of subsequent unnecessary laparotomies. ${ }^{2-6}$ Unfortunately, most of the published literature on this subject are case reports or retrospective analyses; few prospective randomised trials have been undertaken to compare the benefits of laparoscopies versus laparotomies in trauma cases. The present article aims to assess the indications for and outcomes of laparoscopy in trauma patients in comparison to traditional laparotomy methods and to outline the risks and benefits of each procedure.

\section{History}

The first laparoscopic intervention was performed by Stone et al. in 1942 to diagnose internal bleeding in a patient with traumatic injuries. ${ }^{7}$ In 1970, 
Heselson advocated the use of the laparoscopy to detect penetrating injuries and injuries to internal abdominal organs. ${ }^{7}$ Since then, there has been a major improvement in laparoscopic technology and instruments with a corresponding improvement in outcomes. ${ }^{1}$ Ahmed et al. revealed that the laparoscopic technique was both safe and accurate in the management of penetrating abdominal injuries. ${ }^{8}$ The use of laparoscopy has since spread rapidly throughout trauma centres worldwide and is slowly replacing the need for exploratory laparotomies. ${ }^{9}$

\section{Indications for Laparoscopy}

The role of the laparoscopy in screening, diagnosis and therapy has been studied extensively throughout the past few decades. Many studies have confirmed that laparoscopies can be safely performed for patients with a normal haemodynamic status and equivocal abdominal/pelvic computed tomography (CT) or ultrasonography (US).,10,11 The European Association of Endoscopic Surgeons has published evidence-based guidelines for the use of laparoscopies in patients with blunt or penetrating abdominal trauma. ${ }^{12}$ This minimally invasive procedure may potentially prevent non-therapeutic laparotomies; in a study of 819 patients with small bowel injuries, Sitnikov et al. found that video-assisted laparoscopies were associated with postoperative complication and mortality rates of $11.8 \%$ and $2.3 \%$, respectively. ${ }^{13}$

\section{DIAGNOSTIC USE}

Among patients with abdominal trauma, the main concern is a possible injury to the liver or spleen which is not identified during the initial assessment, especially for patients with normal haemodynamic parameters. The use of a laparoscopy in such cases would help to rule out any associated organ injuries or haemorrhage, particularly of the bowel, that were not visible on imaging. While intra-abdominal fluid can usually be seen on CT or US scans, this may either be associated with abdominal trauma or be secondary to resuscitative measures. It is difficult to identify the type of fluid based on diagnostic imaging alone; therefore, a laparoscopy can be utilised in these circumstances to identify the fluid and obtain samples for analysis.

Nonetheless, the diagnostic utility of a laparoscopy depends primarily on the skills of the operating surgeon. In a recent study from Taiwan, two groups of trauma patients underwent either a laparotomy or a laparoscopy carried out by surgeons who had previously performed at least 10 acute care laparoscopies per month. ${ }^{5}$ Laparoscopies were found to have a $100 \%$ sensitivity in detecting injuries; ${ }^{5}$ this suggests that better patient outcomes are associated with increased laparoscopic experience in acute care settings. In the USA, 4,755 out of 2.5 million trauma patients in 467 trauma centres underwent diagnostic laparoscopies between 2007-2010; among these, there was a $0.5 \%$ rate of missed injuries requiring a delayed laparotomy and therapeutic intervention. ${ }^{6}$ This could potentially be due to a reduced level of expertise in the use of minimal invasive surgery in trauma patients. Nevertheless, results from both studies indicated better outcomes for laparoscopic patients in terms of reduced hospital stay and fewer complications. ${ }^{5,6}$

\section{PENETRATING INJURIES}

Penetrating abdominal trauma, including stabbingand gunshot-related wounds, is one of the most common causes of mortality in trauma patients. ${ }^{9}$ This form of trauma does not have to penetrate the peritoneal cavity itself-some injuries can be tangential without violating the peritoneum. In one study, it was estimated that $45 \%$ of patients with normal haemodynamic parameters who sustained a penetrating abdominal wound had a tangential path of injury. ${ }^{14}$ Therefore, there is a need to develop an accurate and sensitive diagnostic modality to identify patients with true penetration of the peritoneum. Laparoscopies have shown superior specificity and sensitivity in identifying peritoneal penetration when compared to $\mathrm{CT}$ and focused assessment with sonography for trauma (FAST). ${ }^{15,16}$ In a study conducted to analyse 10 years of laparoscopy experience in a level-one trauma centre, $83 \%$ of the 131 patients who underwent laparoscopic interventions had a penetrating abdominal injury. ${ }^{1}$ The indications for a laparoscopy in these patients included a gunshot wound involving the flanks, an anterior abdominal stab wound with fascia penetration, evidence of peritonitis on FAST scans and uncertainty regarding the tangential path of injury. Had any of these patients experienced a decline in vital signs, a laparotomy would have been the modality of choice. ${ }^{1}$

\section{DIAPHRAGMATIC INJURIES}

One of the most common injuries associated with penetrating trauma is a diaphragmatic tear or rupture. Thoracoabdominal trauma is any injury within the region bounded by the posterior nipple line superiorly to the costal margin inferiorly. Diaphragmatic injuries should always be suspected in such conditions, as they can be easily missed during the initial diagnosis. Powell et al. found that $20 \%$ of patients who sustained penetration to the thoracoabdominal area developed a diaphragmatic injury. ${ }^{11}$ A study estimating mortality 
and morbidity due to complicated diaphragmatic injuries reported rates of $20 \%$ and $30 \%$, respectively. ${ }^{17}$ The most common complication of a diaphragmatic injury is the herniation of abdominal content into the thorax which, if untreated, can cause complications that can lead to death. ${ }^{17,18}$ Accordingly, ruling out violations or breaches of the diaphragm is crucial. Unfortunately, non-invasive imaging modalities (CT and US) have been associated with high false-negative rates in the diagnosis of diaphragmatic injuries. ${ }^{19,20}$ In addition, Mihos et al. reported that $74 \%$ of traumatic diaphragmatic injuries in their study were diagnosed intra-operatively after being missed initially on noninvasive imaging. ${ }^{21}$ A laparoscopy enables visual examination of the left lobe of the diaphragm and, to a lesser extent, the right lobe, which would otherwise be obscured by the liver on imaging. Direct laparoscopic visualisation of the diaphragm has been shown to be the best diagnostic modality to identify diaphragmatic tears and ruptures. ${ }^{11}$ However, CT scans remain the standard imaging modality in patients involved in trauma.

\section{BLUNT ABDOMINAL TRAUMA}

Non-invasive radiological imaging has shown good sensitivity and specificity in detecting intra-abdominal injuries following blunt abdominal trauma (97\% and 98\%, respectively). ${ }^{22}$ However, there is still a degree of ambiguity involved with certain splenic lacerations and pancreatic or gastrointestinal tract injuries. The indications for the use of a laparoscopy in blunt trauma cases include evidence of a hollow viscous injury on CT scans or peritonitis on physical examination. ${ }^{5}$ Additionally, physical examinations may be unreliable due to a patient's altered mental status. However, as mentioned previously, haemodynamic stability is mandatory in the choice of a laparoscopic intervention over a traditional laparotomy..$^{10}$ Diaphragmatic injuries have also been associated with blunt trauma, manifesting as larger ruptures and tears in comparison to penetrating trauma. These injuries account for $2.1 \%$ of patients with blunt trauma injuries. ${ }^{23}$ Laparoscopic examinations can confirm the presence of blunt trauma injuries but a laparotomy is still essential in cases of large tears. ${ }^{23}$

\section{THERAPEUTIC USE}

The use of a laparoscopy is not limited to screening and diagnostics. Multiple centres worldwide have implemented therapeutic laparoscopies for the management of specific injuries. ${ }^{10}$ Patients with normal haemodynamic parameters and no associated head or chest injuries are ideal candidates for a therapeutic laparoscopic intervention. ${ }^{10}$ In a recent systematic review on the use of laparoscopies in trauma, 20 research papers on therapeutic laparoscopies were identified. ${ }^{9}$ Of the 1,263 patients involved in these studies, 143 therapeutic laparoscopy procedures were performed. The most common injuries repaired were diaphragmatic injuries (54\%), followed by liver and mesenteric injuries (13\% each). ${ }^{9}$ In liver injuries, laparoscopies have been utilised to provide haemostasis by the application of fibrin glue to minimally bleeding lacerations. ${ }^{24}$ Laparoscopies have also been used to wash accumulated blood from the peritoneal cavity as a sequel to intra-abdominal bleeding. This ensures a reduction in associated complications, including peritonitis, ileus and inflammation. ${ }^{25}$ Carrillo et al. reported the use of laparoscopies in suction drainage to evacuate residual fluids and prevent further fluid accumulation. ${ }^{25}$

\section{Contraindications for Laparoscopy}

\section{ABNORMAL HAEMODYNAMICS}

Patients with abnormal haemodynamic parameters are not considered appropriate candidates for laparoscopic interventions. ${ }^{10}$ Suspected major bleeding or an injury which might cause the patient's condition to deteriorate usually calls for urgent surgery. Rapid identification of the bleeding source or critical injury is important in trauma patients; this cannot be carried out efficiently via a laparoscopy.

\section{MULTIPLE ORGAN INVOLVEMENT}

No advantage has been found in the use of a laparoscopy over a laparotomy among patients with injuries involving multiple organs. ${ }^{10}$ In fact, the time required to perform a laparoscopy increases in cases of complicated multiple injuries. Thus, a laparotomy is preferred in such situations as it allows full exploration of the intraperitoneal and retroperitoneal structures and provides more efficient damage control and repair of injuries. ${ }^{10}$

\section{HEAD INJURIES}

Few studies in the literature cover the effect of pneumoperitoneum on intracranial pressure. One report relayed a rise in intracranial pressure among trauma patients managed laparoscopically. ${ }^{26}$ This is thought to be due to an increase in the partial pressure of carbon dioxide, as it is used to provide the pneumoperitoneum required for a laparoscopy. ${ }^{26}$ Therefore, it is advisable to proceed directly with a traditional laparotomy for patients with suspected head injuries. 


\section{Benefits of Laparoscopy}

One of the greatest advantages of laparoscopies in trauma cases is the reduction in the rate of negative or non-therapeutic laparotomies performed; this in turn reduces hospitalisation, laparotomy-associated morbidity and overall costs and improves outcomes. ${ }^{4,5}$ One study found that $50 \%$ of patients who sustained blunt trauma with equivocal findings and underwent a laparoscopy avoided the necessity for a laparotomy. ${ }^{27}$ In other centres, the use of laparoscopic procedures resulted in a $70-80 \%$ reduction in the number of nontherapeutic laparotomies. ${ }^{11,28}$ This reduction may be due to the tremendous improvement in laparoscopic techniques and tools over the past few decades. ${ }^{29}$ Laparoscopy-associated complications and morbidity are significantly lower than in cases of traditional laparotomy. ${ }^{2-4}$ Recent research on the complications associated with diagnostic laparoscopy versus negative laparotomy showed reduced complication rates $(3 \%$ versus $22 \%$ ) and decreased hospital stay (1.4 versus 5.1 days). ${ }^{2}$ Other studies have found that laparoscopies can significantly reduce hospitalisation- and complicationrelated costs when compared to the traditional laparotomy, with an estimated total reduction of $1.78-2$ times. ${ }^{3,4}$

Kaban et al. reported that the laparoscopy had sensitivity and specificity rates of $92 \%$ and $100 \%$, respectively, in detecting injuries. ${ }^{30}$ Another study confirmed the superiority of laparoscopy over diagnostic peritoneal lavage with regards to sensitivity and specificity; additionally, no significant bleeding or trauma was observed during a subsequent laparotomy for $8 \%$ of those in the laparoscopy group compared to $27 \%$ of those in the peritoneal lavage group. $^{31}$ Direct visualisation using laparoscopy has been shown to be more accurate than CT and US in detecting diaphragmatic tears or ruptures and other solid organ injuries. ${ }^{32}$ However, it has been found to have a low sensitivity (20\%) in the identification of hollow viscous injuries. ${ }^{32}$

In a recent systematic review on laparoscopic interventions in trauma cases, only $24.6 \%$ of the research papers had therapeutic applications, the majority of which focused on the laparoscopic repair of diaphragmatic injuries. ${ }^{9}$ The low prevalence of laparoscopy use was thought to be due to a lack of expertise in using laparoscopy in a trauma setting. ${ }^{9}$ Nevertheless, the rate of therapeutic laparoscopy is expected to rise with continuous advancements in the development of new techniques and training programmes. In a randomised control trial, 20 haemodynamically stable patients with no signs of peritonitis underwent an exploratory laparotomy and 23 underwent a diagnostic laparoscopy; there were no statistically significant differences between the two groups, apart from length of hospital stay, which was lower among those who underwent diagnostic laparoscopies. ${ }^{33}$ In the same study, patients with equivocal peritoneal violations underwent either a diagnostic laparoscopy $(\mathrm{n}=28)$ or expectant nonoperative management $(\mathrm{n}=31)$. Diagnostic laparoscopies were performed more often for minor organ injuries; however, there were no statistical differences in therapeutic operation rates, morbidity or hospital costs..$^{33}$

\section{Complications of Laparoscopy}

As with any other invasive procedure, the laparoscopy carries a risk of complications; however, it has been estimated that only $1-11 \%$ of patients undergoing a diagnostic laparoscopy will develop complications related to the procedure. ${ }^{34}$

\section{MISSED INJURIES}

Previously, high rates (up to 77\%) for missed bowel injuries have been reported while using laparoscopies as a screening or diagnostic modality. However, Kawahara et al. reported that a systemic approach for laparoscopic abdominal examinations resulted in the complete absence of missed bowel injuries and high avoidance of unnecessary laparotomies (73.33\%). ${ }^{35}$ Nevertheless, patients with suspected retroperitoneal involvement and those with deteriorating haemodynamic parameters should undergo an open laparotomy to prevent complications secondary to a missed injury.

\section{TENSION PNEUMOTHORAX}

Pneumothorax occurs with the insufflation of air during the laparoscopic procedure when an underlying diaphragmatic injury allows communication between the abdominal and thoracic cavities. If undetected or left untreated, this serious condition can lead to death. Tension pneumothorax is one of the most common laparoscopy-associated complications in trauma patients. ${ }^{29,36}$ It is mandatory to insert a thoracotomy tube in such a situation to prevent further deterioration of the patient's condition..$^{29,36}$

\section{Conclusion}

Laparoscopic interventions in trauma patients with normal haemodynamic parameters are an excellent modality to identify diaphragmatic injuries and peritoneal penetration. In comparison with 
traditional laparotomies, laparoscopies are more efficient and cost-effective and associated with fewer complications. However, clear guidelines to support and indicate the use of laparoscopy in trauma patients are still lacking. Additionally, there is a need for prospective randomised controlled trials to provide stronger evidence for the use of the laparoscopic approach in the management of trauma patients.

\section{References}

1. Johnson JJ, Garwe T, Raines AR, Thurman JB, Carter S Bender JS, et al. The use of laparoscopy in the diagnosis and treatment of blunt and penetrating abdominal injuries: 10-year experience at a level 1 trauma center. Am J Surg 2013;205:317-21. doi: 10.1016/j.amjsurg.2012.10.021

2. Sosa JL, Baker M, Puente I, Sims D, Sleeman D, Ginzburg E, et al. Negative laparotomy in abdominal gunshot wounds: Potential impact of laparoscopy. J Trauma 1995; 38:194-7. doi: 10.1097/00005373-199502000-00007.

3. Taner AS, Topgul K, Kucukel F, Demir A, Sari S. Diagnostic laparoscopy decreases the rate of unnecessary laparotomies and reduces hospital costs in trauma patients. J Laparoendosc Adv Surg Tech 2001; 11:207-11. doi: 10.1089/109264201750539718

4. DeMaria EJ, Dalton JM, Gore DC, Kellum JM, Sugerman HJ Complementary roles of laparoscopic abdominal exploration and diagnostic peritoneal lavage for evaluating abdominal stab wounds: A prospective study. J Laparoendosc Adv Surg Tech A 2000; 10:131-6. doi: 10.1089/lap.2000.10.131

5. Lin HF, Chen YD, Lin KL, Wu MC, Wu CY, Chen SC. Laparoscopy decreases the laparotomy rate for hemodynamically stable patients with blunt hollow viscus and mesenteric injuries. Am J Surg 2015; 210:326-33. doi: 10.1016/j.amjsurg.2014.11.009.

6. Zafer SN, Onwugbufor MT, Hughes K, Greene WR, Cornwell EE 3rd, Fullum TM, et al. Laparoscopic surgery for trauma: The realm of therapeutic management. Am J Surg 2015; 209 : 627-32. doi: 10.1016/j.amjsurg.2014.12.011.

7. Heselson J. Peritoneoscopy in abdominal trauma. S Afr J Surg 1970; 8:53-61.

8. Ahmed N, Whelan J, Brownlee J, Chari V, Chung R. The contribution of laparoscopy in evaluation of penetrating abdominal wounds. I Am Coll Surg 2005; 201:213-16. doi: 10.1016/j.jamcollsurg.2005.04.021.

9. O'Malley E, Boyle E, O'Callaghan A, Coffey JC, Walsh SR. Role of laparoscopy in penetrating abdominal trauma: A systemic review. World J Surg 2013; 37:113-22. doi: 10.1007/s00268012-1790-y.

10. Goettler CE, Bard MR, Toschlog EA. Laparoscopy in trauma. Curr Surg 2004; 61:554-9. doi: 10.1016/j.cursur.2004.06.017.

11. Powell BS, Magnotti LJ, Schroeppel TJ, Finnell CW, Savage SA, Fischer PE, et al. Diagnostic laparoscopy for the evaluation of occult diaphragmatic injury following penetrating thoracoabdominal trauma. Injury 2008; 39:530-4. doi: 10.1016/j.injury.2007.10.020

12. Sauerland S, Agresta F, Bergamaschi R, Borzellino G, Budzynski A, Champault G, et al. Laparoscopy for abdominal emergencies: Evidence-based guidelines of the European Association for Endoscopic Surgery. Surg Endosc 2006; 20: 14-29. doi: 10.1007/s00464-005-0564-0.

13. Sitnikov V, Yakubu A, Sarkisyan V, Turbin M. The role of video-assisted laparoscopy in management of patients with small bowel injuries in abdominal trauma. Surg Endosc 2009; 23:125-9. doi: 10.1007/s00464-008-9910-3.
14. Ivatury RR, Simon FJ, Stahl WM. A critical evaluation of laparoscopy in penetrating abdominal trauma. J Trauma 1993; 34:822-7. doi: 10.1097/00005373-199207000-00054.

15. Guth AA, Pachter HL. Laparoscopy for penetrating thoracoabdominal trauma: Pitfalls and promises. JSLS 1998; 2:123-7.

16. Ivatury RR, Simon RJ, Weksler B, Bayard V, Stahl WM. Laparoscopy in the evaluation of intrathoracic abdomen after penetrating injury. J Trauma 1992; 33:101-8. doi: 10. 1097/00005373-199207000-00019.

17. Hallfeldt KK, Trupka AW, Erhard J, Waldner H, Schweiberer L. Emergency laparoscopy for abdominal stab wounds. Surg Endosc 1998; 12:907-10. doi: 10.1007/s004649900743.

18. Madden MR, Paull DE, Finkelstein JL, Goodwin CW, Marzulli V, Yurt RW, et al. Occult diaphragmatic injury from stab wounds to the lower chest and abdomen. J Trauma 1989; 29:292-8. doi: 10.1097/00005373-198903000-00003.

19. Friese RS, Coln CE, Gentilello LM. Laparoscopy is sufficient to exclude occult diaphragm injury after penetrating abdominal trauma. J Trauma 2005; 58:789-92. doi: 10.1097/01.TA.000015 8243.78299.B5.

20. Mahajna A, Mitkal S, Bahuth H, Krausz MM. Diagnostic laparoscopy for penetrating injuries in the thoracoabdominal region. Surg Endosc 2004; 18:1485-7. doi: 10.1007/s00464-0039296-1.

21. Mihos P, Potaris K, Gakidis J, Paraskevopoulos J, Varvatsoulis P, Gougoutas B, et al. Traumatic rupture of the diaphragm: Experience with 65 patients. Injury 2003; 34:169-72. doi: 10.1016/S0020-1383(02)00369-8.

22. Shanmuganathan K, Mirvis SE, Chiu WC, Killeen KL, Hogan GJ, Scalea TM. Penetrating torso trauma: Triplecontrast helical CT in peritoneal violation and organ injury - A prospective study in 200 patients. Radiology 2004; 231:775-84. doi: 10.1148/radiol.2313030126

23. Rubikas R. Diaphragmatic injuries. Eur J Cardiothorac Surg 2001; 20:53-7. doi: 10.1016/S1010-7940(01)00753-9.

24. Chen RJ, Fang JF, Lin BC, Hsu YB, Kao JL, Kao YC, et al. Selective application of laparoscopy and fibrin glue in the failure of nonoperative management of blunt hepatic trauma. J Trauma 1998; 44:691-5. doi: 10.1097/00005373-19980400000024.

25. Carrillo EH, Reed DN Jr, Gordon L, Spain DA, Richardson JD. Delayed laparoscopy facilitates the management of biliary peritonitis in patients with complex liver injuries. Surg Endosc 2001; 15:319-22. doi: 10.1007/s004640000300.

26. Mobbs RJ, Yang MO. The dangers of diagnostic laparoscopy in the head injured patient. J Clin Neurosci 2002; 9:592-3. doi: 10.1054/jocn.2001.1070.

27. Biffl WL, Kaups KL, Cothren CC, Brasel KJ, Dicker RA, Bullard MK, et al. Management of patients with anterior abdominal stab wounds: A Western Trauma Association multicenter trial. J Trauma 2009; 66:1294-301. doi: 10.1097/ TA.0b013e31819dc688.

28. Saribeyoglu K, Pekmezci S, Baca B, Zengin K, Karatas A, Erenler Kilic I, et al. Laparoscopy offers diagnosis and treatment in abdominal stab injuries. Surg Laparosc Endosc Percutan Tech 2007; 17:396-401. doi: 10.1097/SLE.0b013e3181378e79.

29. Villaviencio RT, Aucar JA. Analysis of laparoscopy in trauma. J Am Coll Surg 1999; 189:11-20. doi: 10.1016/S1072-7515(99) 00052-6.

30. Kaban GK, Novitsky YW, Perugini RA, Haveran L, Czerniach D, Kelly JJ, et al. Use of laparoscopy in evaluation and treatment of penetrating and blunt abdominal injuries. Surg Innov 2008; 15:26-31. doi: 10.1177/1553350608314664. 
31. Cuschieri A, Hennessy TP, Stephens RB, Berci G. Diagnosis of significant abdominal trauma after road traffic accidents: Preliminary results of a multicenter clinical trial comparing minilaparoscopy with peritoneal lavage. Ann R Coll Surg Engl 1988; 70:153-5.

32. Ivatury RR, Simon RJ, Stahl WM. Selective celiotomy for missile wounds of the abdomen based on laparoscopy. Surg Endosc 1994; 8:366-9. doi: 10.1007/BF00642432.

33. Leppäniemi A, Haapiainen R. Diagnostic laparoscopy in abdominal stab wounds: A prospective, randomized study. J Trauma 2003; 55:636-45. doi: 10.1097/01.TA.0000063000. 05274.A4.
34. Society of American Gastrointestinal and Endoscopic Surgeons. Guidelines for diagnostic laparoscopy. From: www.sages.org/ publications/guidelines/guidelines-for-diagnostic-laparoscopy/ Accessed: Sep 2015.

35. Kawahara NT, Alster C, Fujimura I, Poggetti RS, Birolini D. Standard examination system for laparoscopy in penetrating abdominal trauma. J Trauma 2009; 67:589-95. doi: 10.1097/ TA.0b013e3181a60593.

36. Leppäniemi AK, Elliott DC. The role of laparoscopy in blunt abdominal trauma. Ann Med 1996; 28:483-9. doi: $10.3109 / 07853899608999112$. 